\title{
Suzuki type fixed point theorems for generalized multi-valued mappings in $b$-metric spaces
}

\section{Hatairat Yingtaweesittikul}

\section{"Correspondence:}

hatairat.y@gmail.com

Department of Mathematics,

Faculty of Science, Chiang Mai

University, Chiang Mai, 50200,

Thailand

\begin{abstract}
In this paper, we obtained a new condition for a multi-valued mapping in a $b$-metric space, which guarantees the existence of its fixed point.

MSC: $47 \mathrm{H} 10 ; 54 \mathrm{H} 25 ; 54 \mathrm{E} 50$
\end{abstract}

Keywords: fixed point; $b$-metric space; multi-valued mappings

\section{Introduction}

Let $(X, d)$ be a metric space, and let $\mathrm{CB}(X)$ be a collection of all non-empty closed and bounded subsets of $X$. For every $A, B \in \mathrm{CB}(X)$, a Hausdorff metric $H$ induced by the metric $d$ of $X$ is given by

$$
H(A, B)=\max \left\{\sup _{a \in A} d(a, B), \sup _{b \in B} d(b, A)\right\},
$$

where $d(a, B)=\inf \{d(a, x), x \in B\}$.

For a multi-valued mapping $T: X \rightarrow 2^{X}$, a point $x \in X$ is called a fixed point of $T$ if $x \in T x$. We denote the set of fixed points of $T$ by $\operatorname{Fix}(T)$.

Banach's fixed point theorem is extended to the following result of Nadler [1] from the single-valued mappings to the multi-valued contractive mappings.

Theorem 1.1 [1] Let $(X, d)$ be a complete metric space, and let $T: X \rightarrow \mathrm{CB}(X)$ be a setvalued $\alpha$-contraction, that is, a mapping, for which there exists a constant $\alpha \in(0,1)$ such that $H(T x, T y) \leq \alpha d(x, y), \forall x, y \in X$. Then $T$ has at least one fixed point.

The following remarkable generalization of the classical Banach contraction theorem due to Suzuki [2], states the following.

Theorem 1.2 [2] For a metric space $(X, d)$, define a nonincreasing function $\theta$ from $[0,1)$ onto $(1 / 2,1]$ by

$$
\theta(r)= \begin{cases}1 & \text { if } 0 \leq r \leq(\sqrt{5}-1) / 2 \\ (1-r) r^{-2} & \text { if }(\sqrt{5}-1) / 2 \leq r \leq 2^{-1 / 2} \\ (1+r)^{-1} & \text { if } 2^{-1 / 2} \leq r<1\end{cases}
$$

(0) 2013 Yingtaweesittikul; licensee Springer. This is an Open Access article distributed under the terms of the Creative Commons Attribution License (http://creativecommons.org/licenses/by/2.0), which permits unrestricted use, distribution, and reproduction in any medium, provided the original work is properly cited. 
The following are equivalent:

(i) $X$ is complete.

(ii) Every mapping $T$ on $X$ such that there exists $r \in[0,1), \theta(r) d(x, T x) \leq d(x, y)$ implies that $d(T x, T y) \leq r d(x, y)$ for all $x, y \in X$ has a fixed point.

Theorem 1.2 has been generalized to multi-valued mappings by Kikkawa and Suzuki [3], Mot and Petrusel [4], Dhompongsa and Yingtaweesittikul [5], Singh and Mishra [6], Shahzad and Bassindowa [7], and Aleomraninejad et al. [8].

The concept of a $b$-metric space was introduced by Czerwik (see [9] and [10]). We recall from [9] the following definition.

Definition 1.3 [9] Let $X$ be a set, and let $s \geq 1$ be a given real number. A function $d$ : $X \times X \rightarrow R^{+}$is said to be a $b$-metric if and only if for all $x, y, z \in X$, the following conditions are satisfied:

1. $d(x, y)=0$ if and only if $x=y$.

2. $d(x, y)=d(y, x)$.

3. $d(x, z) \leq s[d(x, y)+d(y, z)]$.

A pair $(X, d)$ is called a $b$-metric space.

We remark that a metric space is evidently a $b$-metric space. However, Czerwik (see [9, 10]) has shown that a $b$-metric on $X$ need not be a metric on $X$.

We cite the following lemmas from Czerwik [9-11] and Singh et al. [6]

Lemma 1.4 Let $(X, d)$ be a $b$-metric space. For any $A, B, C \in \mathrm{CB}(X)$ and any $x, y \in X$,

1. $d(x, B) \leq d(x, b)$ for any $b \in B$,

2. $d(x, B) \leq H(A, B)$ for any $x \in A$,

3. $d(x, A) \leq s[d(x, y)+d(y, A)]$.

Lemma 1.5 Let $(X, d)$ be a b-metric space, and let $A, B \in C(X)$. Then for each $\alpha>0$ and for all $b \in B$, there exists $a \in A$ such that

$$
d(a, b) \leq H(A, B)+\alpha .
$$

Some examples of $b$-metric spaces and some fixed point theorems for single-valued and multi-valued mappings in $b$-metric spaces can also be found in Czerwik [9], Boriceanu et al. [12], Boriceanu et al. [13], Aydi and Bota [14], Bota et al. [15], and Bota [16].

Theorem 1.6 [9] Let $(X, d)$ be a b-complete metric space, and let $T: X \rightarrow \mathrm{CB}(X)$ be a multi-valued mapping such that $T$ satisfies the inequality

$$
H(T x, T y) \leq r d(x, y) \quad \text { for all } x, y \in X,
$$

where $0<r<\frac{1}{s}$. Then $T$ has a fixed point.

Theorem 1.7 [16] Let $(X, d)$ be a b-complete metric space, and let $T: X \rightarrow \mathrm{CB}(X)$ be a multi-valued mapping. Suppose that there exist $a, b, c>0$ with $c<1$ and $\frac{a+b}{1-c}<\frac{1}{s}$ such that 
$T$ satisfies the inequality

$$
H(T x, T y) \leq a d(x, y)+b d(x, T x)+c d(y, T y)
$$

for all $x, y \in X$. Then $T$ has a fixed point.

Theorem 1.8 [14] Let $(X, d)$ be a b-complete metric space, and let $T: X \rightarrow \mathrm{CB}(X)$ be a multi-valued mapping such that for all $x, y \in X$,

$$
H(T x, T y) \leq r \max \{d(x, y), d(x, T x), d(y, T y), d(x, T y), d(y, T x)\},
$$

where $r<\frac{1}{s^{2}+s}$. Then $T$ has a fixed point.

In 2011, Aleomraninejad et al. [17] gave a new condition for multi-valued mappings in a metric space, which guarantees the existence of its fixed point.

Consider a continuous function $g:[0, \infty)^{5} \rightarrow[0, \infty)$ satisfying the following conditions:

(i) $g(1,1,1,2,0)=g(1,1,1,0,2)=h \in(0,1)$.

(ii) $g$ is subhomogeneous, that is, for all $\left(x_{1}, x_{2}, x_{3}, x_{4}, x_{5}\right) \in[0, \infty)^{5}, \alpha>0$

$$
g\left(\alpha x_{1}, \alpha x_{2}, \alpha x_{3}, \alpha x_{4}, \alpha x_{5}\right) \leq \alpha g\left(x_{1}, x_{2}, x_{3}, x_{4}, x_{5}\right) .
$$

(iii) If $x_{i}, y_{i} \in[0, \infty), x_{i}<y_{i}$ for $i=1, \ldots, 4$, then

$$
g\left(x_{1}, x_{2}, x_{3}, x_{4}, 0\right)<g\left(y_{1}, y_{2}, y_{3}, y_{4}, 0\right) \text { and } g\left(x_{1}, x_{2}, x_{3}, 0, x_{4}\right)<g\left(y_{1}, y_{2}, y_{3}, 0, y_{4}\right) \text {. }
$$

Theorem 1.9 [17] Let $(X, d)$ be a complete metric space, and let $F, G: X \rightarrow \mathrm{CB}(X)$ be two multi-valued mappings. Suppose that there exist $\alpha \in(0,1)$ and $g \in R$ such that $\alpha(h+1) \leq 1$ and $\alpha d(x, F x) \leq d(x, y)$ or $\alpha d(y, G y) \leq d(x, y)$ implies that

$$
H(F x, G y) \leq g(d(x, y), d(x, F x), d(y, G y), d(x, G y), d(y, F x))
$$

for all $x, y \in X$. Then $\operatorname{Fix}(F)=\operatorname{Fix}(G)$ and $\operatorname{Fix}(F)$ is non-empty.

The aim of this paper is to apply the concept of this function $g$ to $b$-metric spaces.

Let $s \geq 1$ be fixed, and let $R_{s}$ be the set of all continuous functions $g:[0, \infty)^{5} \rightarrow[0, \infty)$ satisfying the conditions (ii), (iii) and

(iv) $g(1,1,1,2 s, 0)=g(1,1,1,0,2 s)=h_{s} \in(0,1 / s)$.

Following the proofs in [18] and [17] with minor modification, we get the following results, respectively.

Lemma 1.10 If $g \in R_{s}$ and $u, v \in[0, \infty)$ are such that

$$
\begin{gathered}
u \leq \max \{g(v, v, u, s(v+u), 0), g(v, v, u, 0, s(v+u)), \\
g(v, u, v, s(v+u), 0), g(v, u, v, 0, s(v+u))\},
\end{gathered}
$$

then $u \leq h_{s} v$. 
Proof Without loss of generality, we can suppose that $u \leq g(v, v, u, s(v+u), 0)$.

If $v<u$, then

$$
u \leq g(v, v, u, s(v+u), 0) \leq g(u, u, u, 2 u s, 0) \leq u g(1,1,1,2 s, 0)=h_{s} u<u
$$

which is a contradiction. Thus $u \leq v$. So,

$$
u \leq g(v, v, u, s(u+v), 0) \leq g(v, v, v, 2 v s, 0) \leq v g(1,1,1,2 s, 0)=h_{s} v .
$$

Lemma 1.11 Let $(X, d)$ be a b-complete metric space, and let $F, G: X \rightarrow \mathrm{CB}(X)$ be two multi-valued mappings. Suppose that there exist $\alpha \in(0, \infty)$ and $g \in R_{s}$ such that $\alpha d(x, F x) \leq d(x, y)$ or $\alpha d(y, G y) \leq d(x, y)$ implies that

$$
H(F x, G y) \leq g(d(x, y), d(x, F x), d(y, G y), d(x, G y), d(y, F x))
$$

for all $x, y \in X$. Then $\operatorname{Fix}(F)=\operatorname{Fix}(G)$.

Proof Let $x \in \operatorname{Fix}(F)$, then $\alpha d(x, F x)=0=d(x, x)$. Thus,

$$
\begin{aligned}
d(x, G x) & \leq H(F x, G x) \\
& \leq g(d(x, x), d(x, F x), d(x, G x), d(x, G x), d(x, F x)) \\
& \leq g(0,0, d(x, G x), d(x, G x), 0) \\
& \leq g(0,0, d(x, G x), s d(x, G x), 0) .
\end{aligned}
$$

Using Lemma 1.10, we have $d(x, G x) \leq h_{s} 0=0$. So, $x \in \operatorname{Fix}(G)$.

Hence $\operatorname{Fix}(F) \subseteq \operatorname{Fix}(G)$. Similarly, we can obtain $\operatorname{Fix}(G) \subseteq \operatorname{Fix}(F)$.

\section{Main results}

Theorem 2.1 Let $(X, d)$ be a b-complete metric space, and let $F, G: X \rightarrow \mathrm{CB}(X)$ be two multi-valued mappings. Suppose that there exist $\alpha \in(0,1)$ and $g \in R_{s}$ such that $\alpha\left(h_{s}+1\right) \leq$ 1 and $\alpha d(x, F x) \leq d(x, y)$ or $\alpha d(y, G y) \leq d(x, y)$ implies that

$$
H(F x, G y) \leq g(d(x, y), d(x, F x), d(y, G y), d(x, G y), d(y, F x))
$$

for all $x, y \in X$. Then $\operatorname{Fix}(F)=\operatorname{Fix}(G)$ and $\operatorname{Fix}(F)$ is non-empty.

Proof The main idea of the proof follows from Theorem 1.9.

By Lemma 1.11, Fix $(F)=\operatorname{Fix}(G)$. Let $r \in\left(h_{s}, \frac{1}{s}\right)$ and $x_{0} \in X$. If $x_{0}$ is not a fixed point, choose $x_{1} \in F x_{0}$ such that $\alpha d\left(x_{0}, F x_{0}\right)<d\left(x_{0}, x_{1}\right)$. Thus,

$$
\begin{aligned}
d\left(x_{1}, G x_{1}\right) & \leq H\left(F x_{0}, G x_{1}\right) \\
& \leq g\left(d\left(x_{0}, x_{1}\right), d\left(x_{0}, F x_{0}\right), d\left(x_{1}, G x_{1}\right), d\left(x_{0}, G x_{1}\right), d\left(x_{1}, F x_{0}\right)\right) \\
& \leq g\left(d\left(x_{0}, x_{1}\right), d\left(x_{0}, x_{1}\right), d\left(x_{1}, G x_{1}\right), s\left[d\left(x_{0}, x_{1}\right)+d\left(x_{1}, G x_{1}\right)\right], 0\right) .
\end{aligned}
$$


By Lemma 1.10, we have $d\left(x_{1}, G x_{1}\right) \leq h_{s} d\left(x_{0}, x_{1}\right)<r d\left(x_{0}, x_{1}\right)$. If $x_{1}$ is not a fixed point, there exists $x_{2} \in G x_{1}$ such that $d\left(x_{1}, x_{2}\right)<r d\left(x_{0}, x_{1}\right)$. Since $\alpha d\left(x_{1}, G x_{1}\right)<d\left(x_{1}, x_{2}\right)$,

$$
\begin{aligned}
d\left(x_{2}, F x_{2}\right) & \leq H\left(F x_{2}, G x_{1}\right) \\
& \leq g\left(d\left(x_{1}, x_{2}\right), d\left(x_{2}, F x_{2}\right), d\left(x_{1}, G x_{1}\right), d\left(x_{2}, G x_{1}\right), d\left(x_{1}, F x_{2}\right)\right) \\
& \leq g\left(d\left(x_{1}, x_{2}\right), d\left(x_{2}, F x_{2}\right), d\left(x_{1}, x_{2}\right), 0, s\left[d\left(x_{1}, x_{2}\right)+d\left(x_{2}, F x_{2}\right)\right]\right) .
\end{aligned}
$$

By Lemma 1.10, we have $d\left(x_{2}, F x_{2}\right) \leq h_{s} d\left(x_{1}, x_{2}\right)<r d\left(x_{1}, x_{2}\right)$.

Similarly, there exists $x_{3} \in F x_{2}$ such that $d\left(x_{2}, x_{3}\right)<r d\left(x_{1}, x_{2}\right)<r^{2} d\left(x_{0}, x_{1}\right)$.

By continuing this process, we obtain a sequence $\left\{x_{n}\right\}$ in $X$ such that

$$
\begin{aligned}
& x_{2 n-1} \in F x_{2 n-2}, x_{2 n} \in G x_{2 n-1}, \quad d\left(x_{n}, x_{n+1}\right) \leq r^{n} d\left(x_{0}, x_{1}\right) \\
& d\left(x_{2 n}, F x_{2 n}\right) \leq h d\left(x_{2 n-1}, x_{2 n}\right) \quad \text { and } \quad d\left(x_{2 n-1}, G x_{2 n-1}\right) \leq h d\left(x_{2 n-2}, x_{2 n-1}\right) .
\end{aligned}
$$

We prove next that the sequence $\left\{x_{n}\right\}$ is Cauchy,

$$
\begin{aligned}
d\left(x_{n}, x_{n+p}\right) \leq & s\left[d\left(x_{n}, x_{n+1}\right)+d\left(x_{n+1}, x_{n+p}\right)\right]=s d\left(x_{n}, x_{n+1}\right)+s d\left(x_{n+1}, x_{n+p}\right) \\
\leq & s d\left(x_{n}, x_{n+1}\right)+s^{2}\left[d\left(x_{n+1}, x_{n+2}\right)+d\left(x_{n+2}, x_{n+p}\right)\right] \\
= & s d\left(x_{n}, x_{n+1}\right)+s^{2} d\left(x_{n+1}, x_{n+2}\right)+s^{2} d\left(x_{n+2}, x_{n+p}\right) \\
\leq & s d\left(x_{n}, x_{n+1}\right)+s^{2} d\left(x_{n+1}, x_{n+2}\right)+s^{3} d\left(x_{n+2}, x_{n+3}\right)+\cdots \\
& +s^{p-1} d\left(x_{n+p-2}, x_{n+p-1}\right)+s^{p-1} d\left(x_{n+p-1}, x_{n+p}\right) \\
\leq & s r^{n} d\left(x_{0}, x_{1}\right)+s^{2} r^{n+1} d\left(x_{0}, x_{1}\right)+s^{3} r^{n+2} d\left(x_{0}, x_{1}\right)+\cdots \\
& +s^{p-1} r^{n+p-2} d\left(x_{0}, x_{1}\right)+s^{p-1} r^{n+p-1} d\left(x_{0}, x_{1}\right), \\
d\left(x_{n}, x_{n+p}\right) \leq & s r^{n}\left(1+s r+s^{2} r^{2}+\cdots+s^{p-2} r^{p-2}+s^{p-2} r^{p-1}\right) d\left(x_{0}, x_{1}\right) \\
\leq & s r^{n}\left(1+s r+s^{2} r^{2}+\cdots+s^{p-2} r^{p-2}+s^{p-1} r^{p-1}\right) d\left(x_{0}, x_{1}\right) \\
= & s r^{n}\left[\frac{1-(s r)^{p}}{1-s r}\right] d\left(x_{0}, x_{1}\right) .
\end{aligned}
$$

Notice that

$$
s r^{n}\left[\frac{1-(s r)^{p}}{1-s r}\right] d\left(x_{0}, x_{1}\right) \rightarrow 0 \quad \text { as } n \rightarrow \infty .
$$

So $\left\{x_{n}\right\}$ is Cauchy, and $x_{n} \rightarrow x$ for some $x \in X$.

Now, we claim that for each $n \geq 1$,

$$
\alpha d\left(x_{2 n}, F x_{2 n}\right) \leq d\left(x_{2 n}, x\right) \quad \text { or } \quad \alpha d\left(x_{2 n+1}, G x_{2 n+1}\right) \leq d\left(x_{2 n+1}, x\right) .
$$

If $\alpha d\left(x_{2 n}, F x_{2 n}\right)>d\left(x_{2 n}, x\right)$ and $\alpha d\left(x_{2 n+1}, G x_{2 n+1}\right)>d\left(x_{2 n+1}, x\right)$ for some $n \geq 1$, then

$$
\begin{aligned}
d\left(x_{2 n}, x_{2 n+1}\right) & \leq s\left[d\left(x_{2 n}, x\right)+d\left(x_{2 n+1}, x\right)\right] \\
& <s\left[\alpha d\left(x_{2 n}, F x_{2 n}\right)+\alpha d\left(x_{2 n+1}, G x_{2 n+1}\right)\right]
\end{aligned}
$$




$$
\begin{aligned}
& \leq s\left[\alpha d\left(x_{2 n}, x_{2 n+1}\right)+\alpha h d\left(x_{2 n}, x_{2 n+1}\right)\right] \\
& =s(\alpha+\alpha h) d\left(x_{2 n}, x_{2 n+1}\right)=s \alpha\left(h_{s}+1\right) d\left(x_{2 n}, x_{2 n+1}\right) .
\end{aligned}
$$

Thus, we get $s \alpha\left(h_{s}+1\right)>1$, which is a contradiction. By using the assumption, for each $n \geq 1$, either

$$
H\left(F x_{2 n}, G x\right) \leq g\left(d\left(x_{2 n}, x\right), d\left(x_{2 n}, F x_{2 n}\right), d(x, G x), d\left(x_{2 n}, G x\right), d\left(x, F x_{2 n}\right)\right)
$$

or

$$
H\left(F x, G x_{2 n+1}\right) \leq g\left(d\left(x, x_{2 n+1}\right), d(x, F x), d\left(x_{2 n+1}, G x_{2 n+1}\right), d\left(x, G x_{2 n+1}\right), d\left(x_{2 n+1}, F x\right)\right) .
$$

Therefore, one of the following cases holds.

(a) There exists an infinite subset $I \subseteq N$ such that

$$
\begin{aligned}
d\left(x_{2 n+1}, G x\right) & \leq H\left(F x_{2 n}, G x\right) \\
& \leq g\left(d\left(x_{2 n}, x\right), d\left(x_{2 n}, F x_{2 n}\right), d(x, G x), d\left(x_{2 n}, G x\right), d\left(x, F x_{2 n}\right)\right)
\end{aligned}
$$

for all $n \in I$.

(b) There exists an infinite subset $J \subseteq N$ such that

$$
\begin{aligned}
d\left(F x, x_{2 n+2}\right) & \leq H\left(F x, G x_{2 n+1}\right) \\
& \leq g\left(d\left(x, x_{2 n+1}\right), d(x, F x), d\left(x_{2 n+1}, G x_{2 n+1}\right), d\left(x, G x_{2 n+1}\right), d\left(x_{2 n+1}, F x\right)\right)
\end{aligned}
$$

for all $n \in J$.

In case (a), we obtain

$$
\begin{aligned}
d(x, G x) \leq & s\left[d\left(x, x_{2 n+1}\right)+d\left(x_{2 n+1}, G x\right)\right] \\
\leq & s\left[d\left(x, x_{2 n+1}\right)+g\left(d\left(x_{2 n}, x\right), d\left(x_{2 n}, F x_{2 n}\right), d(x, G x), d\left(x_{2 n}, G x\right), d\left(x, F x_{2 n}\right)\right)\right] \\
\leq & s\left[d\left(x, x_{2 n+1}\right)\right. \\
& \left.+g\left(d\left(x_{2 n}, x\right), d\left(x_{2 n}, x_{2 n+1}\right), d(x, G x), s\left[d\left(x_{2 n}, x\right)+d(x, G x)\right], d\left(x, x_{2 n+1}\right)\right)\right]
\end{aligned}
$$

for all $n \in I$. Since $g$ is continuous, $d(x, G x) \leq s(g(0,0, d(x, G x), s d(x, G x), 0))$. Using Lemma 1.10, $d(x, G x)=0$. We have $x \in G x$.

In case (b), we obtain

$$
\begin{aligned}
d(x, F x) \leq & s\left[d\left(x, x_{2 n+2}\right)+d\left(x_{2 n+2}, F x\right)\right] \\
\leq & s\left[d\left(x, x_{2 n+2}\right)\right. \\
& \left.+g\left(d\left(x, x_{2 n+1}\right), d(x, F x), d\left(x_{2 n+1}, G x_{2 n+1}\right), d\left(x, G x_{2 n+1}\right), d\left(x_{2 n+1}, F x\right)\right)\right] \\
\leq & s\left[d\left(x, x_{2 n+2}\right)\right. \\
& \left.+g\left(d\left(x, x_{2 n+1}\right), d(x, F x), d\left(x_{2 n+1}, x_{2 n+2}\right), d\left(x, x_{2 n+2}\right), s\left[d\left(x_{2 n+1}, x\right)+d(x, F x)\right]\right)\right]
\end{aligned}
$$


for all $n \in J$. Since $g$ is continuous, $d(x, F x) \leq s(g(0, d(x, F x), 0,0, s d(x, F x)))$. Using Lemma 1.10, $d(x, F x)=0$. We have $x \in F x$. This completes the proof.

Remark 2.2 Taking $s=1$ in Theorem 2.1 (case of metric spaces), we recover Theorem 1.9.

The following result is a consequence of Theorem 2.1.

Corollary 2.3 Let $(X, d)$ be a b-complete metric space, and let $T: X \rightarrow \mathrm{CB}(X)$ be a multivalued mapping. Suppose that there exist $\alpha \in(0,1)$ and $g \in R_{s}$ such that $s \alpha\left(h_{s}+1\right) \leq 1$ and $\alpha d(x, T x) \leq d(x, y)$ implies that

$$
H(T x, T y) \leq g(d(x, y), d(x, T x), d(y, T y), d(x, T y), d(y, T x))
$$

for all $x, y \in X$. Then $T$ has a fixed point.

Corollary 2.4 Let $(X, d)$ be a b-complete metric space, and let $T: X \rightarrow \mathrm{CB}(X)$ be a multivalued mapping. Suppose that there exists $r \in\left(0, \frac{1}{s}\right)$ such that $\frac{1}{s(r+1)} d(x, T x) \leq d(x, y)$ implies

$$
H(T x, T y) \leq r \max \{d(x, y), d(x, T x), d(y, T y)\}
$$

for all $x, y \in X$. Then $T$ has a fixed point.

Proof Let $g \in R_{s}$ by $g\left(x_{1}, x_{2}, x_{3}, x_{4}, x_{5}\right)=r \max \left\{x_{1}, x_{2}, x_{3}\right\}$, where $r<\frac{1}{s}$. Put $\alpha=\frac{1}{s(r+1)}$. Since $h_{s}=r<\frac{1}{s}$ and $s \alpha\left(h_{s}+1\right) \leq 1$, by using Corollary 2.3, $T$ has a fixed point.

Remark 2.5 Corollary 2.4 is an extension of Theorem 1.6.

Corollary 2.6 Let $(X, d)$ be a b-complete metric space, and let $T: X \rightarrow \mathrm{CB}(X)$ be a multi-valued mapping. Suppose that there exists $a, b \in[0,1)$ and $a+2 b<\frac{1}{s}$ such that $\frac{1}{s(1+a+2 b)} d(x, T x) \leq d(x, y)$ implies that

$$
H(T x, T y) \leq a d(x, y)+b d(x, T x)+b d(y, T y)
$$

for all $x, y \in X$. Then $T$ has a fixed point.

Proof Let $g \in R_{s}$ be $g\left(x_{1}, x_{2}, x_{3}, x_{4}, x_{5}\right)=a x_{1}+b\left(x_{2}+x_{3}\right)$, where $a+2 b<\frac{1}{s}$. Put $\alpha=\frac{1}{s(1+a+2 b)}$. Since $h_{s}=a+2 b<\frac{1}{s}$ and $s \alpha\left(h_{s}+1\right) \leq 1$, by using Corollary 2.3, $T$ has a fixed point.

The following examples show that we can apply Corollary 2.3 but cannot apply Theorem 1.8.

Example 2.7 Let $X=[0,1]$ and $d(x, y)=|x-y|^{2}$ for all $x, y \in X$. It is obvious that $d$ is a $b$-metric on $X$ with $s=2$ and $(X, d)$ is complete. Also, $d$ is not a metric on $X$. Define $T: X \rightarrow \mathrm{CB}(X)$ by

$$
T x= \begin{cases}\left\{\frac{1}{3}, \frac{2}{3}\right\} & \text { if } 0 \leq x<1, \\ \left\{\frac{1}{3}\right\} & \text { if } x=1\end{cases}
$$

Let $x, y \in X$. Without loss of generality, take $x \leq y$. 
If $x=y$ or $x, y<1$, then $T x=T y$. Hence $H(T x, T y)=0$.

If $x<1$ and $y=1$, then

$$
H(T x, T y)=\frac{1}{9} \leq \frac{4}{27}=\frac{1}{3} \cdot \frac{4}{9}=\frac{1}{3} d(y, T y) \leq r \max \{d(x, y), d(x, T x), d(y, T y)\},
$$

where $r=\frac{1}{3}<\frac{1}{2}=\frac{1}{s}$. So all the conditions of Corollary 2.4 are satisfied. Moreover, $\frac{1}{3}$ and $\frac{2}{3}$ are the two fixed points of $T$.

On the other hand, if we choose $x=\frac{1}{3}$ and $y=1$, then

$$
\begin{aligned}
H(T x, T y) & =\frac{1}{9}>\frac{1}{6} \cdot \frac{4}{9}=\frac{1}{s^{2}+s} \max \left\{\frac{4}{9}, 0, \frac{4}{9}, 0, \frac{1}{9}\right\} \\
& =\frac{1}{s^{2}+s} \max \{d(x, y), d(x, T x), d(y, T y), d(x, T y), d(y, T x)\} .
\end{aligned}
$$

So we could not apply Theorem 1.8 .

Example 2.8 Let $X=[1, \infty)$ and $d(x, y)=|x-y|^{2}$ for all $x, y \in X$. Then $(X, d)$ is a complete $b$-metric space with $s=2$. Define $T: X \rightarrow \mathrm{CB}(X)$ by

$$
T x=\left[1,1+\frac{x}{2}\right] \text { for all } x \in X
$$

Consider $H(T x, T y)=\frac{1}{4}(x-y)^{2}=\frac{1}{4} d(x, y) \leq r \max \{d(x, y), d(x, T x), d(y, T y)\}$, where $r=\frac{1}{4}<$ $\frac{1}{2}=\frac{1}{s}$ for all $x, y \in X$. So all the conditions of Corollary 2.4 are satisfied. Moreover, 1 and 2 are the two fixed points of $T$.

On the other hand, if we choose $x=1$ and $y=2$, then

$$
\begin{aligned}
H(T x, T y) & =\frac{1}{4}>\frac{1}{6}=\frac{1}{s^{2}+s} \max \left\{1,0,0,0, \frac{1}{4}\right\} \\
& =\frac{1}{s^{2}+s} \max \{d(x, y), d(x, T x), d(y, T y), d(x, T y), d(y, T x)\} .
\end{aligned}
$$

So we could not apply Theorem 1.8.

\section{Competing interests}

The author declares that she has no competing interests.

\section{Acknowledgements}

The author would like to thank referees for their helpful comments and suggestions and Professor Sompong

Dhompongsa for his appreciation and suggestion regarding this work. This work was supported by the Faculty of

Science, Chiang Mai University, Chiang Mai, Thailand.

Received: 3 March 2013 Accepted: 29 July 2013 Published: 14 August 2013

\section{References}

1. Nadler, SB: Multivalued contraction mappings. Pac. J. Math. 30, 475-488 (1969)

2. Suzuki, T: A generalized Banach contraction principle that characterizes metric completeness. Proc. Am. Math. Soc. $136,1861-1869$ (2008)

3. Kikkawa, M, Suzuki, T: Three fixed point theorems for generalized contractions with constants in complete metric spaces. Nonlinear Anal. 69(9), 2942-2949 (2008)

4. Mot, G, Petrusel, A: Fixed point theory for a new type of contractive multivalued operators. Nonlinear Anal., Theory Methods Appl. 70(9), 3371-3377 (2009)

5. Dhompongsa, S, Yingtaweesittikul, H: Fixed points for multivalued mappings and the metric completeness. Fixed Point Theory Appl. 2009, Article ID 972395 (2009) 
6. Singh, SL, Mishra, SN: Fixed point theorems for single-valued and multivalued maps. Nonlinear Anal. 74(6), 2243-2248 (2011)

7. Shahzad, N, Bassindowa, G: Fixed point theorems for Suzuki-generalized nonexpansive mappings with applications. J. Nonlinear Convex Anal. 13(4), 657-666 (2012)

8. Aleomraninejad, SMA, Rezapour, S, Shahzad, N: Convergence of an iterative scheme for multifunctions. J. Fixed Point Theory Appl. 12(1-2), 239-246 (2012)

9. Czerwik, S: Nonlinear set-valued contraction mappings in b-metric spaces. Atti Semin. Mat. Fis. Univ. Modena 46(2), 263-276 (1998)

10. Czerwik, S: Contraction mappings in b-metric spaces. Acta Math. Inf. Univ. Ostrav. 1, 5-11 (1993)

11. Czerwik, S, Dlutek, K, Singh, SL: Round-off stability of iteration procedures for operators in b-metric spaces. J. Nat. Phys. Sci. 11, 87-94 (1997)

12. Boriceanu, $M$, Petrusel, $A$, Rus, IA: Fixed point theorems for some multivalued generalized contractions in $b$-metric spaces. Int. J. Math. Stat. 6(S10), 65-76 (2010)

13. Boriceanu, M, Bota, M, Petrusel, A: Multivalued fractals in b-metric spaces. Cent. Eur. J. Math. 8(2), 367-377 (2010)

14. Aydi, H, Bota, M, Karapınar, E, Mitrovic, S: A fixed point theorem for set-valued quasi-contractions in $b$-metric spaces. Fixed Point Theory Appl. 2012, 88 (2012)

15. Bota, M, Molnar, A, Varga, C: On Ekeland's variational principle in b-metric spaces. Fixed Point Theory 12(2), 21-28 (2011)

16. Bota, M: Dynamical aspects in the theory of multivalued operators. PhD thesis

17. Aleomraninejad, SMA, Rezapour, S, Shahzad, N: On fixed point generalizations of Suzuki's method. Appl. Math. Lett. 24, 1037-1040 (2011)

18. Constantin, A: A random fixed point theorem for multifunctions. Stoch. Anal. Appl. 12(1), 65-73 (1994)

doi:10.1186/1687-1812-2013-215

Cite this article as: Yingtaweesittikul: Suzuki type fixed point theorems for generalized multi-valued mappings in

b-metric spaces. Fixed Point Theory and Applications 2013 2013:215.

\section{Submit your manuscript to a SpringerOpen ${ }^{\circ}$ journal and benefit from:}

- Convenient online submission

- Rigorous peer review

- Immediate publication on acceptance

Open access: articles freely available online

- High visibility within the field

- Retaining the copyright to your article 